Int. J. Dev. Biol. 55: 633-639

doi: $10.1387 / \mathrm{ijdb} .113321 \mathrm{nz}$

\title{
Decorin developmental expression and function in the early avian embryo
}

\author{
NIKOLAS ZAGRIS*, KONSTANTINA GILIPATHI, NIKOLITSA SOULINTZI \\ and KONSTANTINOS KONSTANTOPOULOS \\ Division of Genetics and Cell and Developmental Biology, Department of Biology, \\ University of Patras, Patras, Greece
}

\begin{abstract}
Decorin, a proteoglycan, interacts with extracellular matrix proteins, growth factors and receptors. Decorin expression and spatio-temporal distribution were studied by RT-PCR and immunofluorescence, while decorin function was examined by blocking antibodies in the early chick embryo. Decorin was first detectable at stage XIII (late blastula). During gastrulation (stage HH3-4), decorin fluorescence was intense in epiblast cells immediately adjacent to the streak, and in migrating cells. Decorin fluorescence was intense in endoderm and strong at mesoderm-neural plate surfaces at stage HH5-6 (neurula). At stage HH10-11 (12 somites), decorin fluorescence was intense in myelencephalon and then showed distinct expression patterns along the myelencephaIon axes by stage HH17. Decorin fluorescence was intense in neural crest cells, dorsal aorta, heart, somite and neuroepithelial cells apposing the somite, nephrotome, gut and in pancreatic and liver primordia. Antibody-mediated inhibition of decorin function affected the head-to-tail embryonic axis extension, indicating that decorin is essential for convergent extension cell movements during avian gastrulation. Decorin was also essential for retinal progenitor cell polarization, neural crest migration, somite boundary formation and cell polarization, mesenchymal cell polarization and primary endoderm displacement to the embryo periphery. The embryonic blood vessels were deformed, the dorsal mesocardium was thinned and the cardiac jelly was abnormally thickened in the heart. Decorin is known to modulate collagen fibrillogenesis, a key mechanism of matrix assembly, and cell proliferation. Decorin also appears to be essential for the coordination of cell and tissue polarization, which is an important feature in organ patterning of the embryo.
\end{abstract}

KEYWORDS: convergentextension, gastrulation, cell polarity, neural crest, retinal progenitor cell, somite, endoderm migration

The extracellular matrix micro-environments in the early embryo are a dynamic repository of messages read by developing cells as they are specified to generate various tissues and functioning organ systems (Boucaut et al., 1996; Heinegard, 2009; Zagris et al., 2009). The promiscuous binding properties of proteoglycans activate signaling cascades that affect cell polarity and migration, adhesion, proliferation and survival, specification of cell fates and pattern formation (Harrisson, 1989; Ruoslahti and Yamaguchi, 1991; Iozzo, 1999; Kresse and Schonherr, 2001; Soulintzi and Zagris, 2007; Heinegard, 2009).

Decorin, the small leucine-rich chondroitin/dermatan sulfate proteoglycan, interacts with collagen I, II and IV, fibrin, fibronectin, thrombospondin, the complement component $\mathrm{C} 1 \mathrm{q}$, and binds and sequesters the transforming growth factor beta (TGF- $\beta$ ) and TGF receptor (TGF -R1), epidermal growth factor receptor (EGFR), low-density lipoprotein receptor-related protein (LRP1), insulin- like growth factor receptor (IGF-1R) and its ligand IGF-1, the Met receptor and suppresses $\beta$-catenin a downstream effector of Met (reviews lozzo, 1999; Kresse and Schonherr, 2001; Schaefer and lozzo, 2008) and thus can influence morphogenesis by more than

\footnotetext{
Abbreviations used in this paper: a, dorsal aorta; ar, first aortic arch; b, blood cells; br, brain; c, neural crest; ce, endocardium; cj, cardiac jelly; cm, myocardium; cv, common cardinal vein; $\mathrm{d}$, diencephalon; $\mathrm{dm}$, dorsal mesocardium; $\mathrm{dv}$, ductus venosus; e, epiblast; ec, ectoderm; el, prospective lens ectoderm; em, extracellular matrix; en, endoderm; ep, primary endoderm; g, gut; h, hypoblast; HH, stage according to Hamburger and Hamilton; ht, heart; l, liver; m, migrating mesodermal cells; mc, mesencephalon; me, mesenchymal cells; mn, myelencephalon; mp, splanchnic mesoderm; ms, somatic mesoderm; mt, myotome; n, notochord; ne, nephrotome; np, neural plate; nt, neural tube; o, oral membrane; op, optic vesicles; $p$, pancreatic diverticula; pn, pronephros; pr, pronephric tubule; ps, primitive streak; s, somite; sc, sclerotome; sg, sympathetic ganglion cells; sp, segmental plate; v, vitelline membrane; va, ventral aorta; ve, ventricle.
} 
one mechanism.

The expression and tissue localization of decorin has been studied most extensively in embryos during late organogenesis, in newborn and adult tissues, and in cells in culture (Lennon et al., 1991; Scholzen et al., 1994; review lozzo, 1999). A very important characteristic of the decorin core protein is its ability to bind growth factors and growth factor receptors and this function of decorin may be fundamental to the distribution and processing of extracellular signals that pattern fields of cells (Kresse and Schonherr, 2001). The body plan of the early vertebrate embryo is established during the late blastula and gastrula stages in responses to signaling by members of the TGF- $\beta$, FGF, BMP and Wnt signaling molecules (Grunz, 1996; Gurdon and Bourillot, 2001). In our present work, we studied how early decorin is expressed and where it is localized during early development of the chick embryo from the morula stage (stage $X$ ) to the early stages of organogenesis (stage $\mathrm{HH} 17$, 29 somites, Hamburger and Hamilton, 1951). We then focused on the possible role of decorin in the early embryo using function blocking antibodies.

\section{Results}

\section{Expression of the decorin gene in the early embryo}

The decorin mRNA expression pattern was examined by RTPCR in chick embryos at stages XI (morula), XIII- (mid-blastula), $\mathrm{HH} 2$ (initial streak), $\mathrm{HH} 4$ (definitive streak), $\mathrm{HH} 4-5$ (early neurula) and $\mathrm{HH} 11$ (13 somites) (Fig. 1). Amplification of $\beta$-actin a relatively invariant internal reference RNA was performed in parallel, and cDNA amounts were standardized to equivalent $\beta$-actin mRNA levels. The results showed bands of the predicted size of 517-bp decorin and 187-bp $\beta$-actin (Fig. 1); no products were observed if RNA was omitted from the reaction. We did not detect the predicted 517-bp PCR product in decorin cDNA derived from embryos at stages XI (morula) to XIII- (mid-blastula). It would seem that decorin mRNA starts its expression shortly after the mid-blastula stage because decorin protein was first detected at the late blastula stage (Fig. 2A). Decorin mRNA was detected at the initial streak stage $(\mathrm{HH} 2)$ and its levels were increased more than 3- and12times by the definitive streak $(\mathrm{HH} 4)$ and early neurula $(\mathrm{HH} 4-5)$ stages, respectively. At stage $\mathrm{HH} 11$, decorin gene expression was particularly prominent in the embryonic axis but decorin was not expressed in the area vasculosa (Fig. 1).

\section{Spatiotemporal patterns of decorin}

Decorin protein was first detected by immunofluorescence in the epiblast and the hypoblast in embryos at the late blastula stage (XIII) (Fig. 2A). Midway through gastrulation (stage $\mathrm{HH}$ ) (Fig. 2B) and at the late gastrula stage (HH4) (Fig. 2C), decorin fluorescence was intense in the cells in the epiblast immediately adjacent to the streak, the cells ingressing through the streak and in the migrating mesenchymal cells and the cells of the lower layer (Fig. $2 \mathrm{~B}, \mathrm{C}$ ). This pattern of decorin distribution is intriguing because it points to an active role for decorin in coordinating the polarization and recruitment of epiblast cells that ingress through the streak. At stage HH5-6 (early neurula), decorin fluorescence was intense in endoderm, at moderate levels in mesoderm and was strong at the endoderm- mesoderm-neural plate interphases (Fig. 2D). Decorin which can bind TGF- $\beta$ may regulate the growth factor availability and/or participate in the intercellular communication between the endo-meso-ectodermal inductive signaling which specifies cell fates in all germ layers (Grunz, 1996; Gurdon and Bourillot, 2001).

At stage $\mathrm{HH} 10$-11 (12-somites), decorin expression was intense in the myelencephalon and in neural crest cells emerging from the myelencephalon and migrating along the dorsolateral route beneath the ectoderm and ventromedially along the dorsal aorta and gut walls (Fig. 3 A,B). The dorsal mesocardium, myocardium, endocardium and cardiac jelly of the primitive heart tube showed intense fluorescence. Strong fluorescence was also seen in the ectoderm, endoderm, notochord, the mesenchyme around the dorsal aorta, the dorsal aorta wall and in the extracellular matrix (Fig. 3 A,B). At the somite level of the same embryo, decorin fluorescence showed distinct expression patterns along the neural tube dorsoventral and mediolateral axes (Fig. 3C). Decorin fluorescence was intense in the neuroepithelial cells apposing the somites, in the pronephric duct and lateral mesoderm that will form pronephric tubules, was strong in the ectoderm and the neural crest cells migrating beneath the ectoderm and intense in the somite outer cells, particularly the cells towards the dorsal and lateral aspects of the epithelial somite. This pattern of decorin localization may reflect the participation of decorin in the molecular cross-talk between the somites and their surrounding tissues known to regulate somite patterning and fate determination. In a more posterior section of the same embryo (Fig. 3D), decorin expression was intense in the neural tube cells apposing the segmental plate, strong in

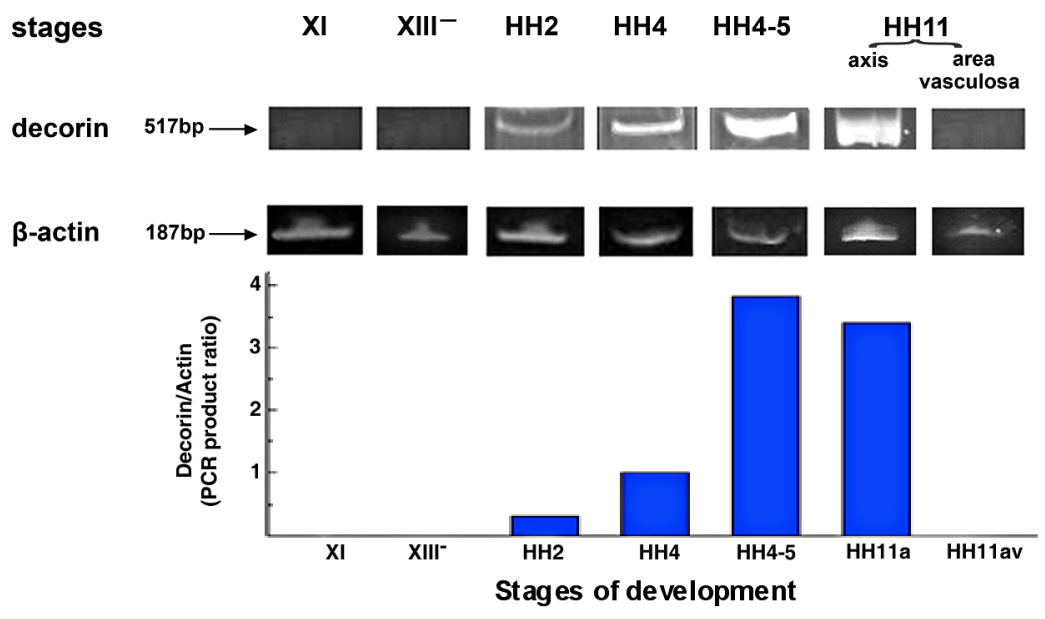

Fig. 1. The expression pattern of the decorin gene in early chick embryo determined by RT-PCR. Representative gel stained with ethidium bromide of RT-PCR amplification products of the 517-bp decorin and the 187-bp $\beta$-actin cDNA produced by specific primers. Total RNA isolated from stages XI (morula), XIII (mid-blastula), HH2 (initial streak), HH4 (definitive streak), HH4-5 (head process) and HH11 (13 somite) of chick embryos was used as template. Embryos at stage HH11 were microdissected and RNA was isolated from the embryonic axis (axis) and the area vasculosa, separately. PCR amplification of $\beta$-actin serves as a load control. Decorin mRNA was not detectable at stage XI and XIII, was expressed at stage HH2 and continued to be expressed at later stages; decorin was not expressed in the area vasculosa. Quantification of decorin mRNA levels determined by scanning densitometryand computer integration of the gel are expressed as a function of $\beta$-actin levels shown schematically in the histogram below the gel. 

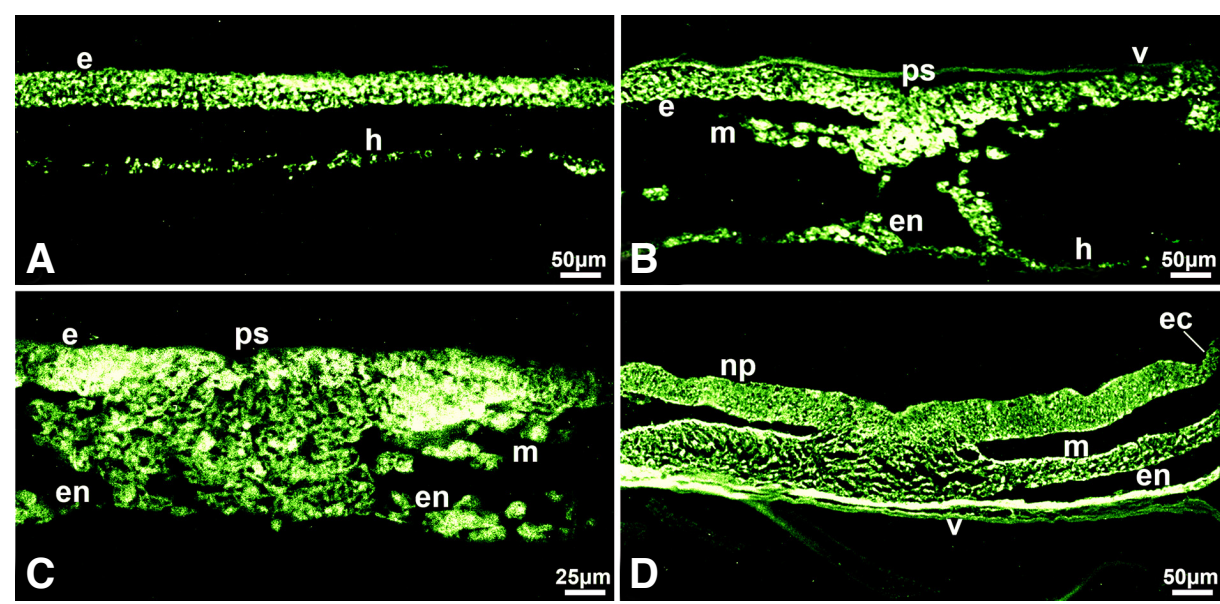

the segmental plate core, in the nephrotome and its neighboring lateral mesoderm, and in the ectoderm and the neural crest cells beneath the ectoderm (Fig. 3D).

In embryos at the 29-somite stage $(\mathrm{HH} 17)$, decorin fluorescence was strong but did not seem to be uniform along the dorsal-ventral and mediolateral myelencephalon axes (Fig. 4 A-C) and this pattern could reflect to an active role of decorin during the dorsal-ventral polarity specification of the neural tube. Decorin fluorescence was intense in the myotome, especially the myocoele, and in neural crest cells stabilized to form the sympathetic ganglia and also in the neural crest cells migrating to the dorsal aorta wall and to the splanchnic mesoderm (secretory lining) apposing the gut wall (Fig. $4 \mathrm{~A}-\mathrm{E})$. Decorin fluorescence was low in the foregut wall but was intense lining the gut lumen and intense in the dorsal and also the ventral pancreatic diverticula and in the liver primordium which sprout from the foregut wall and are known to be under the positive and negative signaling from the notochord, the developing heart and the endothelium of the major blood vessels (Fig. 4 A,D,E). The myocardium, endocardium, ductus venosus of the heart showed intense decorin expression (Fig. 4 A,E,F).

All the control experiments using mouse IgG in place of the antibodies gave rise to negative results (not shown). and Mlodzik, 2008).
Fig. 2. Immunolocalization of decorin in early chick embryos shown on transverse sections. (A) decorin immunoreactivity was distinct in the epiblast and hypoblast of embryos at stage XIII (late blastula). (B,C) cells immediately adjacent and ingressing through the primitive streak, migrating mesodermal cells and endoderm showed intense immunoreactivity in embryos (B) at stage $\mathrm{HH} 3$ (intermediate streak) and (C) at stage $\mathrm{HH} 4$ (definitive streak). (D) decorin immunoreactivity was intense in the endoderm and strong lining the mesoderm surfaces adjacent to the endoderm and to neural plate in embryos at stage HH5-6 (early neurula). Bar, $50 \mu \mathrm{m}$ in $(A, B, D)$ and $25 \mu \mathrm{m}$ in (C).

\section{Perturbation of decorin function}

Embryos exposed to the anti-decorin antibodies at the initial streak stage $\left(\mathrm{HH}_{2}\right)$ displayed a pronounced shortening of the head-to-tail distance (Fig. 5b) but when embryos were exposed to the anti-decorin antibody at the intermediate streak stage $(\mathrm{HH} 3)$, they showed a rather striking phenotype as the head-to-tail axis was significantly elongated and narrowed (Fig. 5c) compared to matched control embryos (Fig. 5a) after $45 \mathrm{~h}$ of culture. The elongated or shortened body axis phenotype of experimental embryos seemed to represent a convergent extension defect.

In reading transverse serial sections, the diencephalon displayed disorganized layering and tears of the neurepithelium and the retinal progenitor cells had formed protrusions in all directions, migrated as differently sized clusters and showed a non-polarized, dispersed pattern (Fig. 5 E, I) compared to the control embryos (Fig. $5 \mathrm{~A}$ ). The caudal neural tube showed defects in closure (Fig. 5L) and these results were very reminiscent of the results obtained in Dishevelled knockout mice which showed that the PCP pathway drives caudal neural tube closure (Hamblet et al., 2002; Simons

Interestingly, neural crest cells had undergone the epithelial-tomesenchymal transition and exited the neural tube but remained
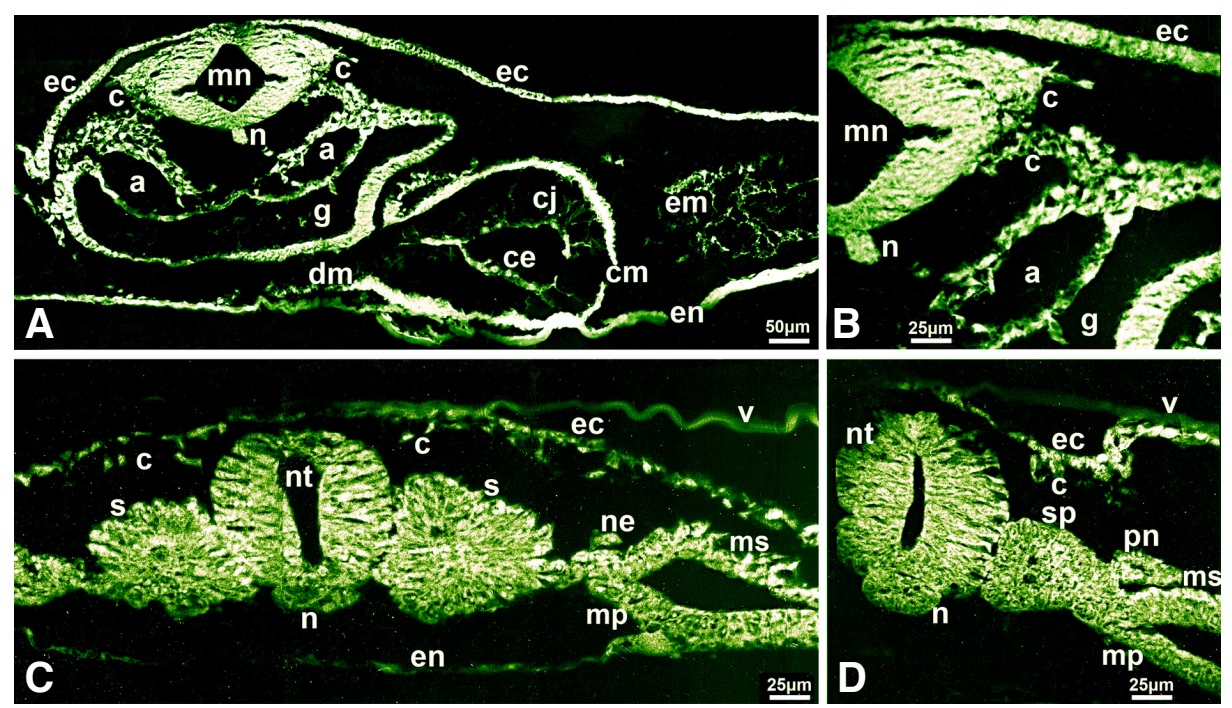
crest cells. (D) In a more posterior section of the same embryo, decorin immunoreactivity was strong in segmental plate, intense in pronephros and adjacent lateral mesoderm, intense in ectoderm and migrating neural crest cells. Bar, $50 \mu \mathrm{m}$ in (A) and $25 \mu \mathrm{m}$ in $(B, C, D)$.
Fig. 3. Immunolocalization of decorin in chick embryo at stage $\mathrm{HH} 10-11$ (12 somites). Transverse sections at the myelencephalon (A,B) and somite $\mathbf{( C , D )}$ regions. $(\mathbf{A})$ decorin immunoreactivity was intense in myelencephalon, notochord, pre-migratory and migrating neural crest cells, gut, in dorsal mesocardium and myocardium and in endocardium, the dorsal aorta and the mesenchyme around the dorsal aorta and the cardiac jelly in heart and extracellular matrix in body cavity; (B) intense decorin fluorescence in neural crest cells emerging from the myelencephalon and migrating ventromedially and dorsolaterally that are shown in (A) presented at higher magnification. (C) At the somite level of the same embryo, decorin immunoreactivity was intense in neuroepithelial cells apposing the somite, in the somitic cells toward the dorsal and lateral aspects of the epithelilized somite, in nephrotome, ectoderm and migrating neural 

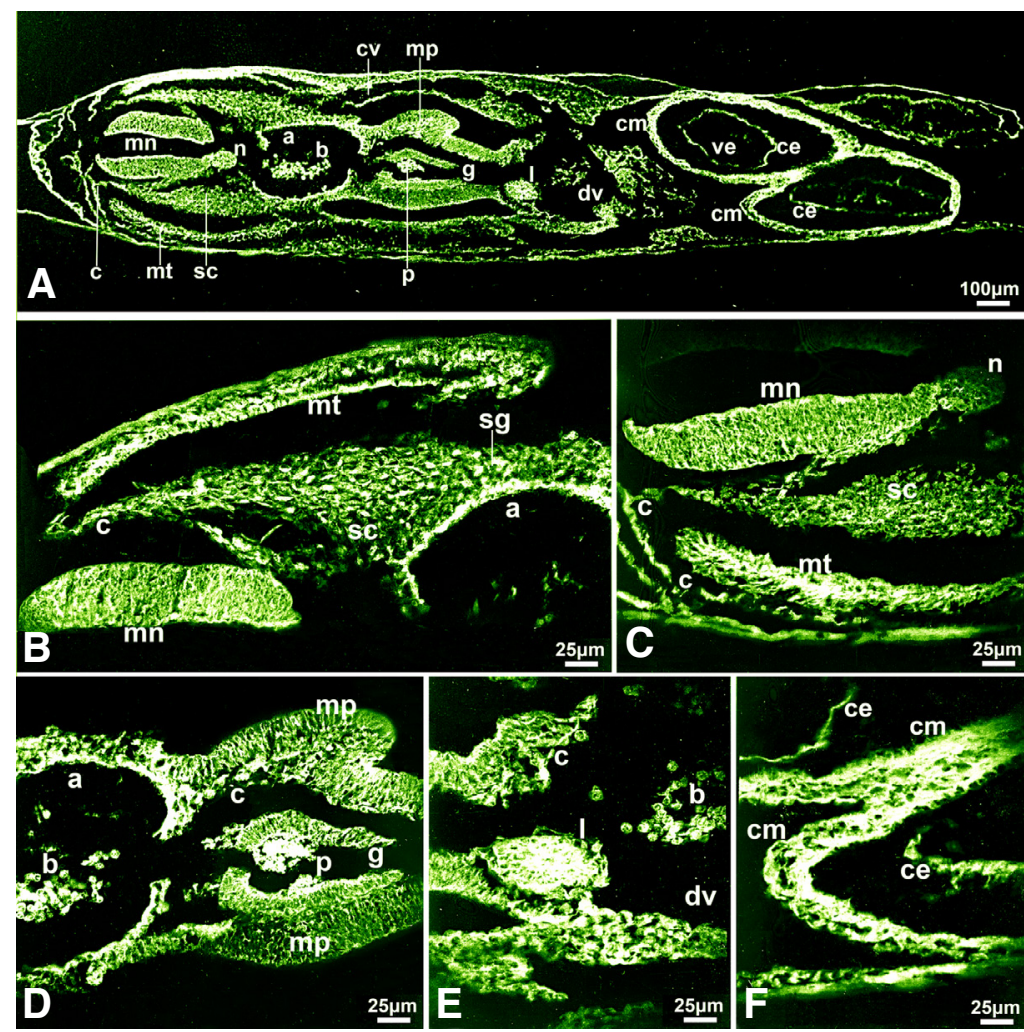

Fig. 4. Immunolocalization of decorin in chick embryo at stage $\mathrm{HH} 17$ (29 somites). (A) Decorin immunoreactivity was strong in the myelencephalon and intense in its lateral and luminal surfaces, intense in migrating neural crest cells, ductus venosus, myocardium, endocardium and dorsal aorta wall, intense in myotome, strong in the splanchnic mesoderm lining the gut, intense lining the gut luminal surface and the liver and pancreatic primordia. (B-F) Higher magnification views of myelencephalon and somite (B,C), dorsal aorta, foregut, splanchnic mesoderm and pancreatic diverticula (D), liver primordium (E), and heart (F) presented in embryonic section (A)or in neighboring sections. Bar, $100 \mu \mathrm{m}$ in (A) and $25 \mu \mathrm{m}$ in (B-F). developed putative somites and somite duplications along both the dorsoventral and mediolateral axes and showed impaired intersomitic boundary formation (Fig. $5 c)$. In transverse sections, blocks of somitic cells were discernable but the cells were unable to epithelialize and appeared randomly distributed in small clusters (Fig. 5L). In the embryos exposed to the anti-decorin antibodies at stage $\mathrm{HH}$, the paraxial mesoderm showed a normal segmental pattern (Fig. $5 b$ ) as compared to control embryos (Fig. 5 b,D). However, somitic cells had not progressed to compartmentalization and there was cell disorientation and random distribution of cells in the myotome and collapse of the dermomyotome within the somite (Fig. 5H). Recent studies suggested involvement of signaling through the non-canonical Wnt pathway in myotomal cell specification (Chen et al., 2005; Brunelli et al., 2007).

Another interesting observation from our results was that the hypoblast-derived endoderm was not displaced to the periphery of the embryo but appeared to persist and even to proliferate and the yolk sac failed to extend in the embryos treated with the anti-decorin antibodies (Fig. $5 \mathrm{~N}$ ) as compared to control embryos (Fig. 5M). In a recent study (Costello et al., 2009), embryoid body outgrowth assays demonstrated that TGF- $\beta / S$ mad 4 regulates endoderm migratory capabilities in vitro and pointed out that TGF- $\beta /$ Smad signals required for guiding endodermal cell migration at early stages of development are only starting to be revealed. It would seem from our present study that decorin, which can bind TGF- $\beta$, participates in the signaling pathway(s) that guides endodermal cell migration in the early embryo. Also, of note, the yolk sac ruffling (Fig. $5 \mathrm{~N}$ ) in decorin suppressed embryos could originate from the loss of adhesiveness between the endoderm and extraembryonic mesoderm and/or overproliferation of primary endoderm. stalled as an epithelial sheet on top of the neural tube unable to converge and migrate when decorin signaling was inhibited by the anti-decorin antibodies (Fig. 5 G,H,J-L). Decorin seemed to specify cell polarity and migration which was also manifested in the alignment of mesenchymal cells that seemed unable to polarize and orient properly along the body axis midline (Fig. 5 F,J).

All the decorin suppressed embryos formed heart and blood vessels, albeit with several abnormalities (Fig. $5 \mathrm{~F}-\mathrm{H}, \mathrm{J}-\mathrm{L}$ ). The dorsal and ventral aortae walls were not defined because the cells seemed non-polarized and disoriented and the aortae were distended and severely deformed (Fig. 5 F,G,J,K). The embryos exposed to the anti-decorin antibodies at the initial streak stage $(\mathrm{HH} 2)$ formed a heart that had not progressed beyond the linear heart tube stage and the extracellular matrix was disorganized (Fig. 5G). The embryos exposed to the anti-decorin antibodies at the intermediate streak stage $(\mathrm{HH})$ formed the heart but the dorsal mesocardium was thinned and the cardiac jelly was abnormally thickened and this could reflect changes in the pattern of deposition for extracellular matrix (Fig. 5K) when compared to that seen in the control embryos (Fig. 5C).

The segmental patterning was perturbed in the embryos exposed to the anti-decorin antibodies at stage $\mathrm{HH} 3$ which

\section{Discussion}

The results from our present study showed that decorin expression was first detectable at the late blastula stage (XIII). Expression of decorin was transient and in spatially restricted patterns during the development of the early chick embryo. Immunodetection of decorin was intense in cell populations undergoing polarization and convergent extension during gastrulation and organ patterning. Inhibition of decorin function resulted in pronounced shortening or elongation of the head-to-tail axis depending on the stage the embryos were exposed to the anti-decorin blocking antibodies (Fig. 5b,c), and this pointed to an important role for decorin in the signaling cascade for the convergent and extension cell movements during avian gastrulation. An important observation from our results was the intense decorin fluorescence in the epiblast cells immediately adjacent to the streak presumably fated to ingress and also in the cells ingressing through the streak (Fig. $2 \mathrm{~B}, \mathrm{C})$. It is possible that decorin, in concert with growth factors, co-ordinates the polarization of epiblast cells that ingress through the streak and in that way can influence cell recruitment and can regulate the numbers of cells joining the streak during its anterior progression. Recent work has shown that growth factor signaling is 
critical for the movement of cells during primitive streak formation and also for the control of coordinated cell movement through the streak (Chuai et al., 2006). Convergent and extension cell movements during vertebrate gastrulation define the shaping of the anterior-posterior and medial-lateral embryonic axes and are largely mediated by the non-canonical $\beta$-catenin-independent Wnt/Planar Cell Polarity (Wnt/PCP) pathway triggered by Wnt11 through the Frizzled receptors to recruit the Dishevelled at the cell membrane and to activate regulators of actin dynamics including the Rho, Rac and Cdc42 GTPases, ROCK and JNK (Chuai et al., 2006; reviewed in Roszko et al., 2009). In Xenopus, zebrafish and mammals, mutations in the Wnt/PCP pathway genes impair the convergence and extension and display severe shortening of the anterior-posterior axis and widening of the notochord and somites (review Roszko et al., 2009). In a recent study, decorin morpholinos injected in 2-cell stage zebrafish embryos caused a pronounced shortening of the head-to-tail axis and this decorin morphant phenotype was considered to represent a convergent extension defect (Zoeller et al., 2009).

In our present work, decorin was also essential for the neural crest polarization and migration, the polarization of mesenchymal cells, and for the displacement of the primary endoderm to the periphery of the embryo. Detailed analyses revealed disorganized layering and discontinuity of the diencephalon neuroepithelium and retinal progenitor cell disorientation in the forming optic vesicles most possibly due to impaired polarized cell behavior. Moreover, the inhibition of decorin function affected the somite boundary formation and led to a segmentation defect and also affected the polarity and distribution of cells within the somite. The embryonic blood vessels were distended and severely deformed, the dorsal mesocardium was thinned and the extracellular matrix (cardiacjelly) was abnormally thickened in the heart. Previous work reported that
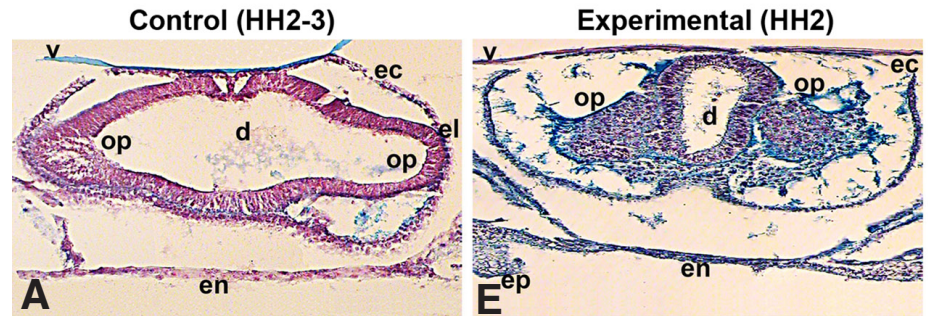

Experimental ( $\mathrm{HH} 3)$
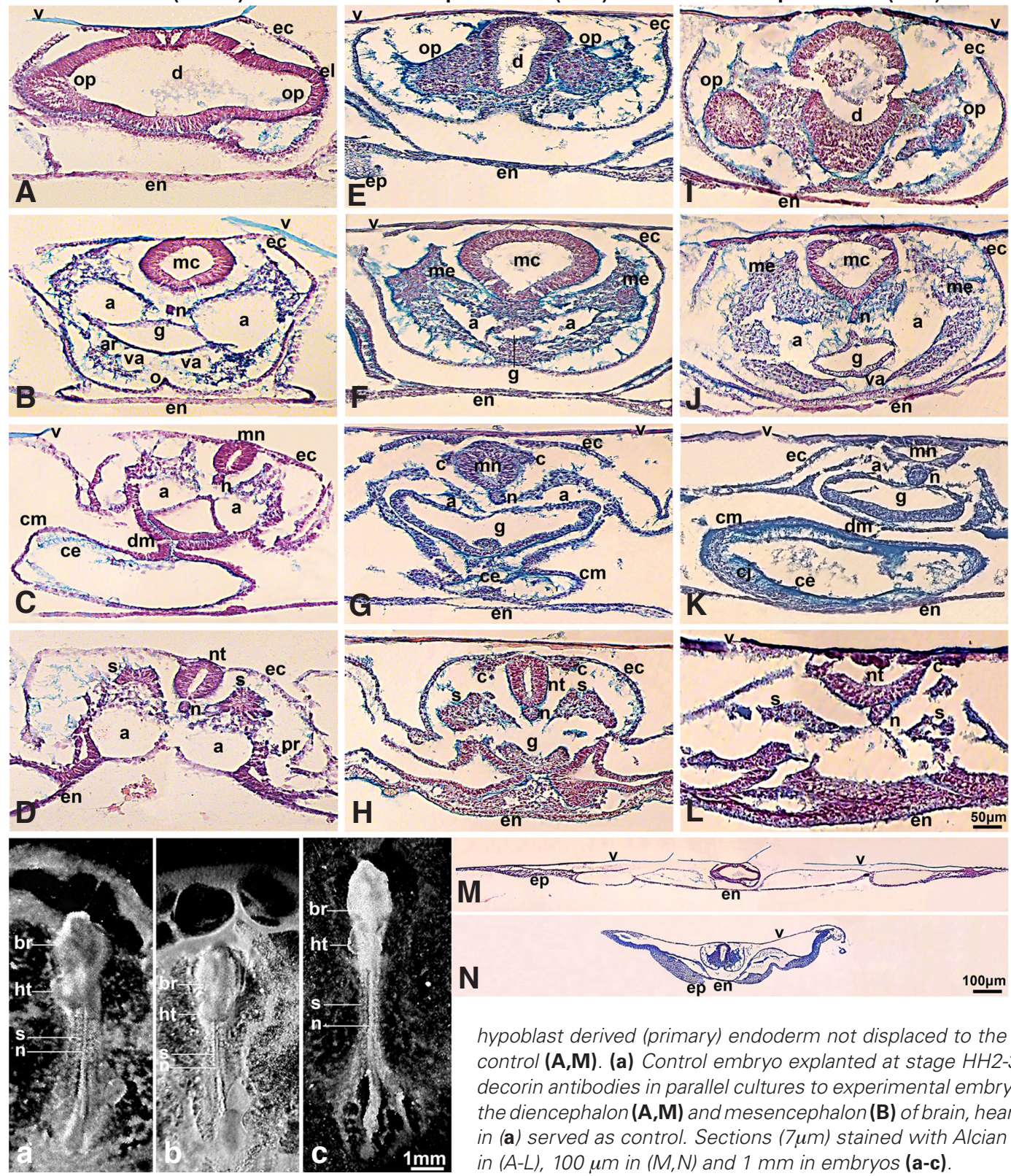
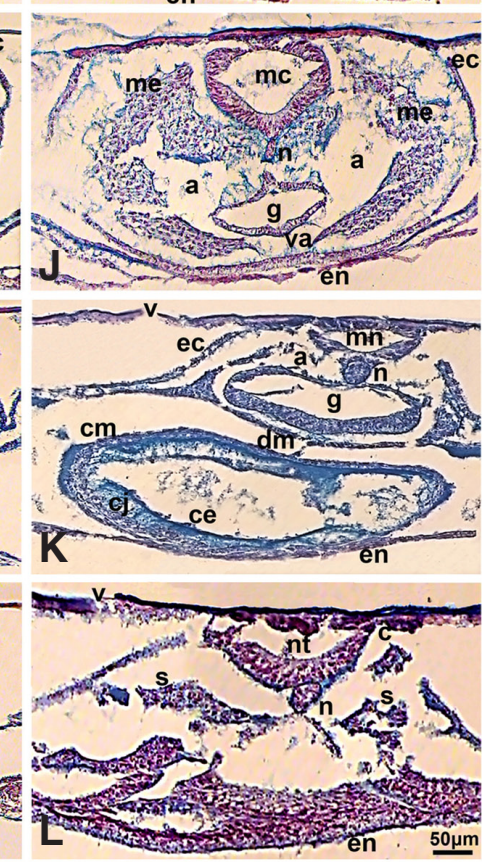

Fig. 5. Monoclonal anti-decorin antibody perturbed specific morphogenetic processes in chick embryo. Embryos at stages $\mathrm{HH} 2$ (initial streak) and HH3 (intermediate streak) were treated either with monoclonal lgG directed at chick decorin (experimental) or nonimmune mouse lgG (control) for $2 h$ then cultured on plain egg albumen for 45h. (b) Embryo exposed to anti-decorin antibody at stage $\mathrm{HH} 2$ displayed pronounced shortening of the head-to-tail axis compared to control embryos (a). (c) Embryo exposed to anti-decorin antibody at stage $\mathrm{HH} 3$ formed a significantly elongated and narrowed head-to-tail axis. (E-H,N) and (I-L) are transverse sections of the embryos (b) and (c), respectively. (E,I) Transverse sections through the diencephalon, $(\mathbf{F}, \mathbf{J})$ mesencephalon, $(\mathbf{G}, \mathbf{K})$ heart, and $\mathbf{( H , L )}$ somite regions showed disorganized layering and tears of the diencephalon wall, retinal progenitor cell disorientation in the forming optic vesicles, impeded neural crestcell migration, impeded displacement of primary endoderm to the embryo periphery, impaired polarization of the somitic and mesenchymal cells, and severely deformed dorsal aorta and ventral aorta, thinned dorsal mesocardium and thickened cardiac jelly in the heart. (N) Lower magnification view of section shown in (E) showed the hypoblast derived (primary) endoderm not displaced to the periphery of embryo as compared to control (A,M). (a) Control embryo explanted at stage HH2-3 and cultured in the absence of antidecorin antibodies in parallel cultures to experimental embryos. (A-D) Transverse sections through the diencephalon (A, M) and mesencephalon (B) of brain, heart (C) and somite (D) regions of embryo in (a) served as control. Sections (7 $\mu \mathrm{m})$ stained with Alcian blue and nuclear fast red. Bar, 50 um in (A-L), $100 \mu \mathrm{m}$ in $(\mathrm{M}, \mathrm{N})$ and $1 \mathrm{~mm}$ in embryos (a-c) 
decorin knockout mice displayed mainly skin laxity and significant fragility manifested at the ultrastructural level by abnormal collagen fibrillogenesis and developed tumors in the intestine (Danielson et al., 1997). The lack of any other anatomical abnormality or any other effect in the decorin-null mice came by surprise because of the wide expression and the importance of decorin in the activation of various cell signaling cascades and the regulation of many physiological and pathological processes (Scholzen et al., 1994; Iozzo, 1999; Kresse and Schonherr, 2001; Schaefer and lozzo, 2008; Goldoni et al., 2009).

Decorin is known to modulate collagen fibrillogenesis, a key mechanism of matrix assembly, and cell proliferation (lozzo, 1999; Kresse and Schonherr, 2001). Decorin appears to be an essential molecular player in signaling pathways that regulate cell movement and motile functions at many key steps to control cell and tissue polarity in the early embryo. Further experiments will have to focus on understanding precisely the position of decorin in signaling cascades, and how decorin co-operates with other factors for polarized cell movements and tissue morphogenesis.

\section{Materials and Methods}

\section{Reverse transcription-PCR (RT-PCR)}

Total RNA was prepared (RNeasy Mini Kit protocol, Qiagen) from chick embryos at stages XI (morula), XIII- (mid blastula), HH2 (initial streak/ early gastrula), $\mathrm{HH} 4$ (definitive streak/late gastrula), $\mathrm{HH} 4-5$ (head process/early neurula) and $\mathrm{HH} 11$ (13 somite); in the embryos at stage $\mathrm{HH} 11$, the embryonic axis was micro-dissected and separated from the extraembryonic area which included the area vasculosa. Attention was paid to the exact developmental stage of the embryos according to Hamburger and Hamilton (HH symbol) (1951). PCR primers were 5'- CTG GAG TTG ATG AAC TGA G-3' (sense, position -21) and 5'- ACT GCT TTC CTC AAC TTG G-3' (antisense, position 497) specific for a fragment of 517-bp (from -21 to 497) of quail decorin mRNA. For $\beta$-actin, a fragment of 187 -bp was amplified with the following primers: sense 5'- CGG TAT TGT CAC CAA CTG G-3' and antisense 5'- TGG CTA CAT ACA TGG CTG G-3' were used in a parallel reaction as the decorin primers. The quail decorin and chick $\beta$-actin primers were the same as those published previously (Corpuz et al., 2000). Single stranded cDNA was synthesized employing as template $2 \mu \mathrm{g}$ of total RNA from embryos according to the manufacturer OneStep RT-PCR Kit protocol (Qiagen); the RNA was omitted from the reaction in the negative control samples. PCR amplification products $(15 \mu \mathrm{l} / \mathrm{lane}$ and $2 \mu \mathrm{l} / \mathrm{lane}$ for decorin and $\beta$-actin, respectively) were separated on a $5 \%$ polyacrylamide gel and stained with ethidium bromide. A 100-10000bp ladder was used as a marker (GeneRuler DNA Ladder Mix, Fermentas). The bands were quantified by a laser scanning densitometry and computer integration (Scion Image PC). The values were normalized to the $\beta$-actin transcript level.

\section{Embryos and decorin immunolabeling}

Embryos at stages X (morula), XIII (late blastula), HH3 (intermediate streak/mid gastrula, Hamburger and Hamilton, 1951), HH4 (definitive streak/ late gastrula) $\mathrm{HH} 5-6$ (head process/early neurula), $\mathrm{HH} 10-11$ (12 somites) and $\mathrm{HH} 17$ (29 somites) were removed from their eggs. The embryos were subsequently fixed in Carnoy fixative (formula B), were dehydrated through graded ethanol solutions, embedded in paraffin and sectioned $(7 \mu \mathrm{m})$ serially. Serial sections from embryos and immunolabeling were performed as described previously (Soulintzi and Zagris, 2007; Zagris et al., 2009). The chick monoclonal anti-decorin antibody (clone CB-1, Lennon et al., 1991) was used at a final concentration of $10 \mu \mathrm{g} / \mathrm{ml}$ in PBS and the sections were incubated overnight at $37.5^{\circ} \mathrm{C}$ in a moist chamber. The fluorescein-conjugated goat anti-mouse IgG secondary antibody (Santa Cruz Biotech., USA) was used at a final concentration of $5 \mu \mathrm{g} / \mathrm{ml}$ in PBS for $1 \mathrm{~h}$ at $37.5^{\circ} \mathrm{C}$ in a moist chamber. The sections were rinsed 3 times (20 min each) in PBS and mounted in glycerol-Mowiol 4-88. Sections were observed and photographed (magnification powers 20 and 40X) with epifluorescent illumination, using filters selective for fluorescein. For control slides, primary antibody was omitted and sections were incubated with mouse IgG and with fluoresceinated secondary antibody. The monoclonal antibody that recognizes an epitope on the chick decorin core protein (clone CB-1, Lennon et al., 1991) was obtained from the Developmental Studies Hybridoma Bank (University of lowa, lowa City, IA, USA).

\section{Function blocking decorin antibodies}

Embryos at stages $\mathrm{HH} 2$ (initial streak/ early gastrula) and $\mathrm{HH} 3$ (intermediate streak/mid gastrula) were removed from their eggs and were placed in $400 \mu \mathrm{l}$ Ringer solution containing the chick monoclonal anti-decorin antibody CB-1 $(2.5 \mu \mathrm{g} / \mathrm{ml}$ final concentration) in a microwell (G20 culture slide; Arthur Thomas, Philadelphia, Pa., USA) and incubated for $1.5 \mathrm{~h}$ at $37.5^{\circ} \mathrm{C}$. At the end of the incubation period, the embryos were washed in Ringer solution, and cultured as described previously (Soulintzi and Zagris, 2007; Zagris et al., 2009). Embryos incubated in plain Ringer solution or in Ringer solution containing non-immune mouse serum, then cultured on plain egg albumen in a parallel culture, served as controls. Embryos were photographed after 45-50 h in culture, fixed in Carnoy fixative, dehydrated, embedded in paraffin and sectioned $(7 \mu \mathrm{m})$ serially. Sections were deparaffinized and stained in Alcian blue (stains both sulfated and non-sulfated proteoglycans) and counterstained with Nuclear fast red (stains nuclei) (Alcian blue method, pH 2.5) (Soulintzi and Zagris, 2007) to study how the absence of decorin had affected the extracellular matrix integrity and the tissue/organ organization of the early embryo. Embryos at the gastrula stage (stages $\mathrm{HH} 2$ and $\mathrm{HH} 3$ ) were used because this stage is critical for establishing the vertebrate body plan. Fifty embryos (15 controls, 35 experimental) were used in the course of this investigation. Embryos, culture media and glassware were handled with sterile precautions.

\section{Acknowledgements}

This work was supported by grants from the European Social Fund (ESF), Operational Program for Educational and Vocational Training II (EPEAEK II) particularly the Program "PYTHAGORAS II" and from the University of Patras ("K. Karatheodori" grant B.397).

\section{References}

BOUCAUT, J.-C., CLAVILIER, L., DARRIBERE, T., DELARUE, M., RIOU, J.-F. and SHI, D.L. (1996). What mechanisms drive cell migration and cell interactions in Pleurodeles? Int. J. Dev. Biol. 40: 675-683.

BRUNELLI, S., RELAIX, F., BAESSO, S., BUCKINGHAM, M. and COSSU, G. (2007). Beta catenin independent activation of MyoD in presomitic mesoderm requires PKC and depends on Pax3 transcriptional activity. Dev. Biol. 304: 604-614.

CHEN, A.E., GINTY, D.D. and FAN, C.M. (2005). Protein kinase A signalling via CREB controls myogenesis induced by Wnt proteins. Nature 433: 317-322.

CHUAI, M., ZENG, W., YANG, X., BOYCHENKO, V., GLAZIER, J.A. and WEIJER, C.J. (2006). Cell movement during chick primitive streak formation. Dev. Biol. 296: 137-149.

CORPUZ, L.M., DUNLEVY, J.R., HASSELL, J.R., CONRAD, A.H. and CONRAD, G.W. (2000). Molecular cloning and relative tissue expression of decorin and lumican in embryonic quail cornea. Matrix Biology 19: 699-704.

COSTELLO, I., BIONDI, C.A., TAYLOR, J.M., BIKOFF, E.K. and ROBERTSON, E.J. (2009). Smad4-dependent pathways control basement membrane deposition and endodermal cell migration at early stages of mouse development. BMC Dev. Biol. 9: 54.

DANIELSON, K.G., BARIBAULT, H., HOLMES, D.F., GRAHAM, H., KADLER, K.E. and IOZZO, R.V. (1997). Targeted disruption of decorin leads to abnormal collagen fibril morphology and skin fragility. J. Cell Biol. 136: 729-743.

GOLDONI, S., HUMPHRIES, A., NYSTROM, A., SATTAR, S., OWENS, R.T., McQUILLAN, D.J., IRETON, K. and IOZZO, R.V. (2009). Decorin is a novel antagonistic ligand of the Met receptor. J. Cell Biol. 185: 743-754.

GRUNZ, H. (1996). Factors responsible for the establishment of the body plan in the 
amphibian embryo. Int. J. Dev. Biol. 40: 279-289.

GURDON, J.B. and BOURILLOT, P.-Y. (2001). Morphogen gradient interpretation. Nature 413: 796-803.

HAMBLET, N.S., LIJAM, N., RUIZ-LOZANO, P., WANG, J., YANG, Y., LUO, Z., MEI, L., CHIEN, K.R., SUSSMAN, D.J. and WYNSHAW-BORIS, A. (2002). Dishevelled 2 is essential for cardiac outflow tract development, somite segmentation and neural tube closure. Development 129: 5827-5838.

HAMBURGER, V. and HAMILTON, H.L. (1951). A series of normal stages in the development of the chick embryo. J. Morphol. 88: 49-92

HARRISSON, F. (1989). The extracellular matrix and cell surface, mediators of cell interactions in chicken gastrulation. Int. J. Dev. Biol. 33: 417-438.

HEINEGARD, D. (2009). Proteoglycans and more- from molecules to Biology. Int. J. Exp. Pathol. 90: 575-586.

IOZZO, R.V. (1999). The biology of the small leucine-rich proteoglycans: Functional network of interactive proteins. J. Biol. Chem. 274: 18843-18846.

KRESSE, H. and SCHONHERR, E. (2001). Proteoglycans of the extracellular matrix and growth control. J. Cell. Physiol. 189: 266-274.

LENNON, D.P., CARRINO, D.A., BABER, M.A. and CAPLAN, A.I. (1991). Generation of a monoclonal antibody against avian small dermatan sulfate proteoglycan: immunolocalization and tissue distribution of PG-II in embryonic tissues. Matrix 11: $412-427$.
ROSZKO, I., SAWADA, A. and SOLNICA-KREZEL, L. (2009). Regulation of convergence and extension movements during vertebrate gastrulation by the Wnt/PCP pathway. Semin. Cell Dev. Biol. 20: 986-997.

RUOSLAHTI, E. and YAMAGUCHI, Y. (1991). Proteoglycans as modulators of growth factor activities. Cell 64, 867-869.

SCHAEFER, L. and IOZZO, R.V. (2008). Biological functions of the small leucinerich proteoglycans: From genetics to signal transduction. J. Biol.Chem. 283: 21305-21309.

SCHOLZEN, T., SOLURSH, M., SUZUKI, S., REITER, R., MORGAN, J.L., BUCHBERG, A.M., SIRACUSA, L.D. and IOZZO, R.V. (1994). The murine decorin: Complete cDNA cloning, genomic organization, chromosomal assignment, and expression during organogenesis and tissue differentiation. J. Biol. Chem. 269: 28270-28281.

SIMONS, M. and MLODZIK, M. (2008). Planar cell polarity signaling: From fly development to human disease. Annu. Rev. Genet. 42: 517-540.

SOULINTZI, N. and ZAGRIS, N. (2007). Spatial and temporal expression of perlecan in the early chick embryo. Cells Tissues Organs 186: 243-256.

ZAGRIS, N., DIMIROPOULOS, A., KONSTANTOPOULOS, K. and CHRISTOPOULOS, M. (2009). Integrin $\alpha 6$ during early development of the avian embryo. Trends Dev. Biol. 4: 19-32.

ZOELLER, J.J., PIMTONG, W., CORBY, H., GOLDONI, S., IOZZO, A.E., OWENS R.T., HO, S.-Y. and IOZZO, R.V. (2009). A central role for decorin during vertebrate convergent extension. J. Biol. Chem. 284: 11728-11737. 
Further Related Reading, published previously in the Int. J. Dev. Biol.

Expression of Wnts in the developing murine secondary palate

Dennis R. Warner, Henry S. Smith, Cynthia L. Webb, Robert M. Greene and M. Michele Pisano

Int. J. Dev. Biol. (2009) 53: 1105-1112

Neural crest ontogeny during secondary neurulation: a gene expression pattern study in the chick embryo

Liliana Osório, Marie-Aimée Teillet, Isabel Palmeirim and Martin Catala Int. J. Dev. Biol. (2009) 53: 641-648

Early stages of neural crest ontogeny: formation and regulation of cell delamination

Chaya Kalcheim and Tal Burstyn-Cohen

Int. J. Dev. Biol. (2005) 49: 105-116

ISI Impact Factor $(2010)=2.86$

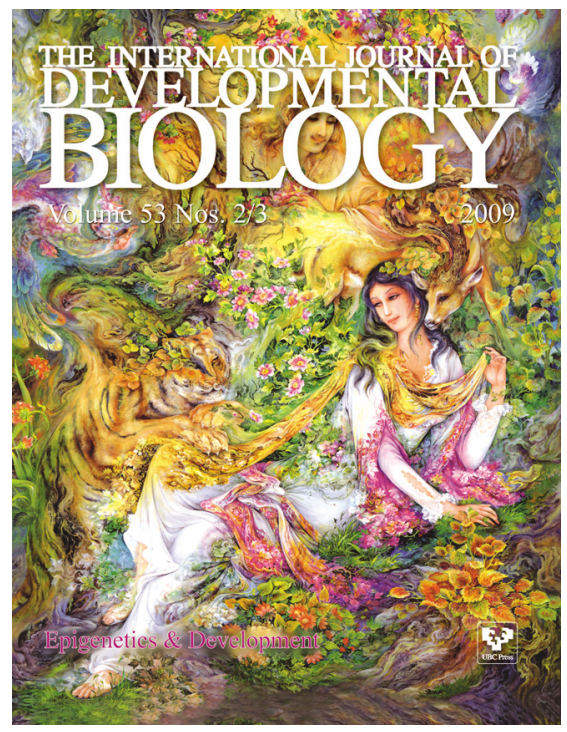

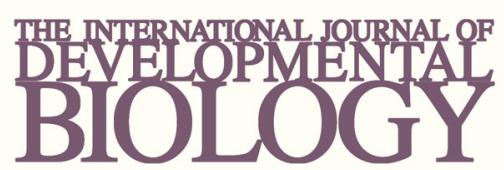

Volume 54 Nos. 6/7
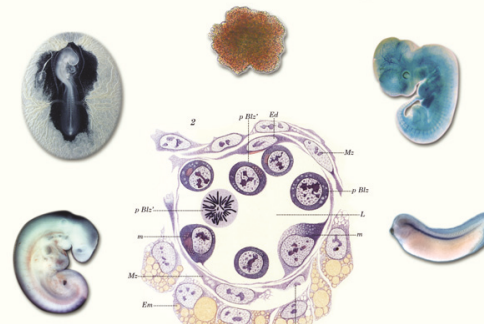

Developmental Hematopoiesis
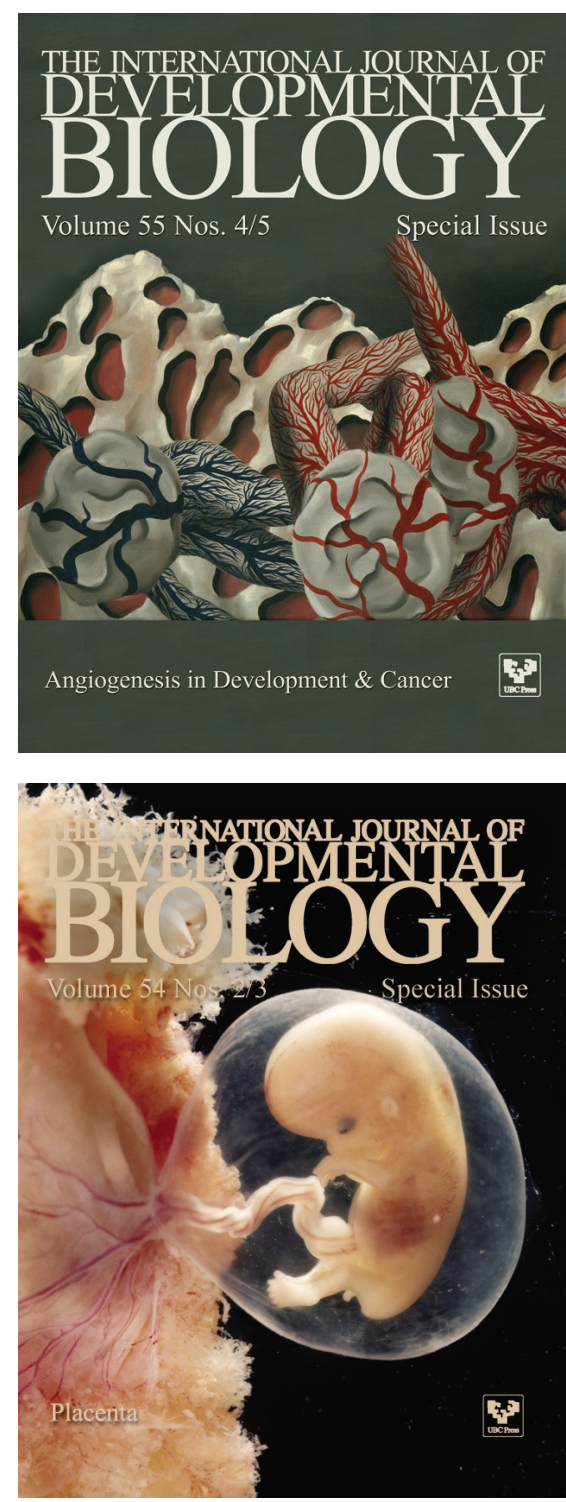